Moral Identity Predicts the Development of Presence of Meaning during Emerging Adulthood

\author{
Hyemin Han \\ University of Alabama \\ Indrawati Liauw* \\ Stanford University \\ Ashley Floyd Kuntz* \\ University of Alabama at Birmingham
}

\begin{abstract}
Author Note
Hyemin Han, Assistant Professor, Educational Psychology Program, University of Alabama.

Indrawati Liauw, PhD Candidate, Graduate School of Education, Stanford University.

Ashley Floyd Kuntz, Assistant Professor, Department of Human Studies, University of Alabama at Birmingham
\end{abstract}

Correspondence concerning this manuscript should be addressed to Hyemin Han, Educational Psychology Program, University of Alabama, Box 870231, Tuscaloosa, AL 35487-0231, USA.

* These authors contributed equally to this work

Acknowledgement: This work was conducted as part of the Civic Purpose project at the Stanford Center on Adolescence under the direction of William Damon, Principal Investigator. The authors thank Heather Malin, Anne Colby, William Damon, and anonymous reviewers for their constructive comments and suggestions; and Parissa Ballard and Tenelle Porter for their 
contributions. This project was supported by a Spencer Foundation New Civics Initiative grant (Grant number: \#201400010).

The final publication will be available at Emerging Adulthood (https://us.sagepub.com/enus/nam/emerging-adulthood/journal202127) pending minor revisions. 
Moral Identity Predicts the Development of Presence of Meaning during Emerging Adulthood 


\begin{abstract}
We examined change over time in the relationship between moral identity and presence of meaning during early adulthood. Moral identity refers to a sense of morality and moral values that are central to one's identity. Presence of meaning refers to the belief that one's existence has meaning, purpose, and value. Participants responded to questions on moral identity and presence of meaning in their senior year of high school and two years after. Mixed effects model analyses were used to examine how moral identity and presence of meaning interacted during this twoyear period. The findings demonstrated that moral identity positively predicted presence of meaning over time.
\end{abstract}

Keywords: moral identity, presence of meaning, meaning in life, positive youth development, transitional period 
Moral Identity Predicts the Development of Presence of Meaning during Emerging Adulthood

The transitional period between adolescence and adulthood has long been associated with identity formation (Erikson, 1968), but only more recently have scholars given attention to meaning in life within this segment of the lifespan. Taken together, these domains describe the process of forming a sense of self and constructing meaning in life. Thus, positive youth development scholars may have reason to be interested in how identity and meaning in life develop over time and to what extent they may be interrelated or mutually reinforcing. At the heart of this growing body of research is a concern for how youths develop a sense of purposeful agency that is not only good for their own development but also for society (Malin, Ballard, \& Damon, 2015).

\section{Meaning in Life}

Steger et al. (2006) defined meaning in life as "the sense made of, and significance felt regarding, the nature of one's being and existence" (p. 81). This definition remains neutral on the content of what makes one's life meaningful and focuses instead on personal constructions of meaning. Presence of meaning, which can be measured by Meaning in Life Questionnaire (MLQ) (Steger, Frazier, Oishi, \& Kaler, 2006), has been associated with less depression, greater self-esteem and optimism, more positive affect, and a greater appreciation for and satisfaction with life (Adams, Bezner, Drabbs, Zambarano, \& Steinhardt, 2000; Fry, 2000; Peterson, Park, \& Seligman, 2005; Reker \& Wong, 1988; Steger et al., 2006). Moreover, higher presence of meaning prevents risky health behaviors in youths, including drug use, unsafe sex, lack of exercise, and overeating (Brassai, Piko, \& Steger, 2011). Developing meaning in life appears to be aided by eudaimonic (i.e., purposeful) rather than hedonistic (i.e., pleasure-seeking) activities. 
Indeed, individuals who engaged in eudaimonic activities (e.g., expressing gratitude, volunteering, and giving) were significantly more likely to report higher presence of meaning and life satisfaction the day following this type of purposeful activity compared to their counterparts who engaged in hedonistic activities (Steger, Kashdan, \& Oishi, 2008).

Of course, the other dimension in MLQ, search for meaning, also contributes eventually to positive youth development and identity development (Steger, Bundick, \& Yeager, 2011). However, search for meaning per se is less directly related to positive psychological outcomes compared to presence of meaning. Steger, Kashdan, Sullivan, and Lorentz (2008) reported that although search for meaning leaded to presence of meaning, it was associated with several negative mental statuses, e.g., anxiety. They showed that presence of meaning was more directly and immediately correlated with positive mental and psychological indicators, e.g., purpose in life and perceived well-being. The similar trend has been reported by other studies as well (Park, Park, \& Peterson, 2010; Steger \& Kashdan, 2007).

Meaning in life is linked to identity development among youths. Longitudinal research found a bidirectional, mutually reinforcing relationship between meaning in life and identity development (Negru-Subtirica, Pop, Luyckx, Dezutter, \& Steger, 2016). While search for meaning dovetailed with identity exploration, presence of meaning predicted identity commitment. Youths who developed a "purposeful worldview" and understood their lives to be meaningful internalized this meaning into a sense of self and acted in ways consistent with this burgeoning identity. Similarly, identity commitments bolstered presence of meaning (NegruSubtrica et al., 2016).

\section{Moral Identity Development}


Much of the existing literature on youth identity development focuses on identity exploration and commitment but pays less attention to the content of one's identity (Hardy et al., 2013). However, a recent study of 9,500 students at 31 universities concluded that "not all identity commitments are equally conducive to healthy functioning; moral commitments may be particularly adaptive" (Hardy et al., 2013, p. 337). This result underscores that moral identity development is closely associated with flourishing.

Moral identity is understood as a motivating factor for moral behavior that helps explain whether a person follows through on doing what she or he knows is the right thing to do (Blasi, 2013; Freeman, Aquino, \& McFerran, 2009; Reed, Aquino, \& Levy, 2007). Certain features of moral identity take on greater salience among youths given other cognitive and social development advances occurring at the same time. While children are typically motivated to behave morally for fear of punishment or desire for praise, adolescents are motivated to a greater extent by internal factors (Hardy \& Carlo, 2011). They begin to understand themselves as individuals with agency in and social responsibility to the social world, and recognize that the social world is complex and seek to develop consistency and integrity in the ways they respond to the demands of social life (Krettenauer et al., 2016; Hardy \& Carlo, 2011).

The development of moral identity, similar to the development of meaning in life, has been associated with a variety of positive youth development indicators. Moral identity has been linked to a greater sense of purpose and social responsibility (Hardy, Walker, Olsen, Woodbury, \& Hickman, 2014). In addition, college students with stronger moral identity have less anxiety and depression, less alcohol use and sexual risk-taking behaviors, and report higher levels of self-esteem and meaning in life (Hardy et al., 2013). 
Of course, identity formation can occur in multiple domains, e.g., religious, career, or academic identity, and such identities in multiple domains influence and moderate well-being (Hardy et al., 2013; Meca et al., 2017). Thus, it would not be possible to argue that moral identity is the sole or most fundamental factor determining flourishing. However, moral identity is at least one of the most critical determinants of flourishing, as previous studies have demonstrated that moral aspects are central to describe one's identity (Strohminger \& Nichols, 2014), and morality is regarded as the fundamental factor to perceive and evaluate happiness among both ordinary people and psychologists (Phillips, De Freitas, Mott, Gruber, \& Knobe, 2017).

\section{The Present Study}

The present study aims to elucidate the relationships between presence of meaning and moral identity. Existing research shows these are important elements that contribute to positive youth development, but few studies have examined whether and how these constructs interrelate and interact over time. Aristotelian moral philosophers have argued that the habituation and internalization of moral virtues into one's self is essential to achieve eudaimonic happiness, which is tied to meaningfulness (Kristjánsson, 2013; Seligman, 2011), as opposed to mere hedonistic happiness (Han, 2015; Kristjánsson, 2012). Thus, the formation of meaning and moral identity development are understood to be conceptually linked. However, empirical exploration of this relationship is nascent. Wetherell (2015) found that regarding moral standards as important to oneself significantly predicted the formation of meaning in life compared to nonmoral conventional standards. In addition, Hardy et al. (2013) reported a significant association between measured moral identity and presence of meaning. These initial findings raise the question of whether moral identity and meaning in life may develop simultaneously or be mutually reinforcing. 
Though much of the existing literature on the development of these constructs has been cross-sectional in nature, we adopted a two-wave analysis design to better understand how these constructs develop over time and to what extent they may be interrelated with one another during emerging adulthood. Drawing from previous developmental psychological studies related to the association between morality and life meaning (Hardy et al., 2013; Negru-Subtirica et al., 2016), we hypothesized that moral identity and presence of meaning would positively contribute to the development of each other over time.

\section{Methods}

\section{Participants}

<Place Table 1 about here>

The present study initially collected survey data from 1,555 Californian high schoolers from seven high schools located in Northern, Central, and Southern California (see Table 1 for the distribution of participants according to gender and ethnicity). Participants were invited to complete survey forms online by researchers who visited the high schools in person. The dataset was collected by Ballard, Malin, Porter, Colby, and Damon (2015) and Malin, Han, and Liauw (2017) using Qualtrics. The title of the survey presented to participants was "Civic Purpose Survey." At T1, all participants were $12^{\text {th }}$ graders, and 17.33 years of age in average $(S D=.43$ years). A follow-up survey at T2 was conducted two years after the initial survey at T1. At T2, 470 participants responded to the survey (attrition rate $=69.77 \%$ ) (see Table 1 for attrition rate according to gender and ethnicity). Although the attrition rate was significantly different across gender, $\mathrm{X}^{2}(1, N=1,555)=22.57, p<.001, \phi=.12$, and ethnicity groups, $\mathrm{X}^{2}(6, N=1,555)=$ 30.72, $p<.001, \phi=.14$, the effect size was small $(.10 \leq \Phi<.30)$. Finally, we conducted Little's Missing Completely at Random test (Little, 1988) to examine whether the data was missing at 
random and results were not biased due to missing values. The result of the test reported that the data was missing at random without significant systematic biases, $\mathrm{X}^{2}(5)$ distance $=1.96, p=.85$.

\section{Measures}

Meaning in Life Questionnaire. We employed the presence of meaning subscale in the Meaning in Life Questionnaire (Steger et al., 2006). Given the more direct and immediate association between presence of meaning and positive psychological indicators, e.g., purpose in life and perceived well-being, compared to search for meaning (Park et al., 2010; Steger \& Kashdan, 2007; Steger, Kashdan, Sullivan, et al., 2008), we decided to focus on the presence of meaning subscale in the present study. This subscale assesses the extent to which an individual believes s/he has identified a sense of purpose and meaning in life. Five items (e.g., "I understand my life's meaning," "My life has a clear sense of purpose") are included in this subscale. Each item is rated on a five-point Likert scale anchored at $1=$ strongly disagree and $5=$ strongly agree, and two items are reverse-scored. The internal consistency quantified in terms of Cronbach's $\alpha$ was .71 at T1 and .76 at T2.

Moral identity. Moral identity was measured with the moral identity subscale included in the civic and moral identity questionnaire developed by the Stanford Center on Adolescence (Bundick et al., 2006; Porter, 2013). Participants read a list of values and then responded to the question, "how important are each of the following to your identity." A total of 16 values were presented. Items included both moral (e.g., "being fair," "honest") and non-moral values (e.g., "smart," "athletic"). Each value item was rated on a four-point Likert scale anchored at $1=$ not at all central to my identity and $4=$ very central to my identity. The final moral identity score was calculated by averaging the perceived centrality of morality-related values (e.g., being fair, 
willing to stand up for what I believe is right). The calculated Cronbach's $\alpha$ was .88 at T1 and .89 at $\mathrm{T} 2$.

Demographics. In addition to the above-mentioned variables on presence of meaning and moral identity, we also asked participants to indicate their gender, ethnic background, socioeconomic status (SES), and college attendance at T2. In the case of surveying SES, we asked participants to report the perceived deciles of the overall wealth, educational and vocational status of their family compared with the overall US people.

\section{Procedures}

The survey was hosted online using Qualtrics. We first recruited $12^{\text {th }}$ graders in California at T1. Participants were provided with an internet link to access the survey form. Two years after T1, the study researchers again contacted each participant via email and phone call, and sent participants an internet link to the Qualtrics survey page. The same online survey form used at $\mathrm{T} 2$.

\section{Analysis}

We conducted correlational analysis in order to examine association between T1 and 2 variables of interest, and demographical variables. Then, we conducted mixed-effects model ANCOVA to examine change over time in the relationship between the development of presence of meaning and moral identity (Rausch, Maxwell, \& Kelley, 2003). First, we created three different models with different independent variables and covariates. The first model included only the variable that was being analyzed (T1 moral identity or $\mathrm{T} 1$ presence of meaning) to control for the pre-test baseline. In the second model, we added demographical variables, i.e., gender, ethnicity, SES. The third model included the T1 independent variable of interest, T1 moral identity when $\mathrm{T} 2$ presence of meaning was set as the independent variable, and $\mathrm{T} 1$ 
presence of meaning when T2 moral identity was set as the independent variable. In all three models, participant's ID and school affiliation were included as random effects to test whether the school-level factor influenced outcomes. We then compared the Akaike information criterion (AIC) and Bayesian information criterion (BIC) values of these models to identify the model with the smaller AIC and BIC values, and thus better fits the data (Aho, Derryberry, \& Peterson, 2014). Furthermore, we calculated the intra-class correlation coefficient (ICC) to examine whether the school-level effect significantly influenced T2 dependent variables.

\section{Results}

\section{Correlational analyses}

$<$ Place Table 2 about here $>$

The correlational coefficients between $\mathrm{T} 1$ and $\mathrm{T} 2$ variables of interest, and demographical variables are presented in Table 2. Descriptive statistics were also presented in the same table. The correlational analyses demonstrated that moral identity and presence of meaning at both time points were positively correlated.

\section{Model selection}

$<$ Place Table 3 about here $>$

To identify the model that best fits the data, we compared the AIC and BIC values among the four different models. The AIC and BIC value for each model is presented in Table 3. According to the reported criterion values for the case of the analysis of T2 presence of meaning, the third model showed the smallest AIC and BIC values. However, in the case of the analysis of T2 moral identity, the AIC was smallest in the third model, but the BIC was smallest in the second model. In order to use the same model for both analyses, we decided to employ the third 
model, which included the T1 baseline, demographical variables and T1 independent variable of interest, based on the AIC and $\log L$ values.

\section{Mixed effects model analysis}

\section{$<$ Place Figure 1 and Table 4 about here $>$}

Using the third model, we conducted mixed effects model analyses with two dependent variables (see Table 4). First, when presence of meaning was the dependent variable, the baseline presence of meaning and T1 moral identity significantly predicted T2 presence of meaning. Second, when moral identity was the dependent variable, the baseline moral identity was the only significant predictor of T2 moral identity.

Given the significant effect of T1 moral identity on T2 presence of meaning after controlling for $\mathrm{T} 1$ presence of meaning, moral identity positively influenced long-term presence of meaning. Participants with T1 moral identity scores that were higher than the median showed a slight decline in their presence of meaning scores from $\mathrm{T} 1$ to $\mathrm{T} 2$, while participants with $\mathrm{T} 1$ moral identity scores that were lower than the median had a steeper decline in their presence of meaning scores from T1 to T2 (see Figure 1). However, T1 presence of meaning did not significantly influenced T2 moral identity.

The analysis of ICC demonstrated that the school-level effect was very small or small in our analyses. When $\mathrm{T} 2$ presence of meaning was set as the dependent variable, the calculated ICC value was .15. In the case of the analysis of T2 moral identity, the ICC was .03. These results suggest that the effect of the school-level factor on T2 dependent variables was not large.

\section{Discussion}

Findings from our regression analysis partially supported our hypothesis. T1 moral identity positively predicted T2 presence of meaning while controlling for the baseline (T1) 
presence of meaning, however, the effect of $\mathrm{T} 1$ presence of meaning on $\mathrm{T} 2$ moral identity was insignificant. This finding may be explained by the fact that the presence of meaning construct remains neutral on the content of what makes one's life meaningful (Steger et al., 2006). In other words, youths may construct meaning of their lives in ways that are not oriented towards expressively moral ends (e.g., finding meaning through being a star athlete or student). Thus, the mere presence of meaning does not necessarily promote moral identity. However, the findings from this study suggest that developing a moral identity does predict presence of meaning. Presumably, the content of this meaning of life would be prosocial in nature, but further research is needed to test this assumption.

We found decline in presence of meaning during emerging adulthood, although moral identity alleviated such a trend. Unfortunately, there have been few previous studies examining change in presence of meaning during emerging adulthood. Several Developmental psychological studies focusing on purpose (Damon, 2008), which is perhaps conceptually related to meaning in life, showed the developmental trend during emerging adulthood. Malin et al.'s (2017) study reported significant decline in civic engagement, which indicates the presence of civic purpose, after graduation from high school. Moreover, Malin, Reilly, Quinn, and Moran's (2014) qualitative study demonstrated relatively more young adults lost their purpose compared to high schoolers. These studies might suggest that early emerging adulthood is involved in the radical change in human life, transition from interdependent life (before high school) to independent life (after high school), so people during this period perhaps experience a risky period in the formation of purpose of and meaning in life (Smith, Christoffersen, Davidson, \& Herzog, 2011). Given the increased searching for meaning and purpose during this period reported by previous studies (Bronk, Hill, Lapsley, Talib, \& Finch, 2009; Steger, Oishi, \& 
Kashdan, 2009), the temporary decrease in presence of meaning can be understood as a process of seeking long-term meaning in life.

For studies of prosocial development, our findings related to moral identity would be informative. The previous research reported that moral identity measured by the same questionnaire used in the present study was positively associated with overall civic engagement and participation in voluntary activity and expressive political activity (Porter, 2013). Furthermore, moral identity measured by the moral centrality questionnaire was positively associated with prosocial behavior (Aquino, Freeman, Reed, Lim, \& Felps, 2009; Aquino \& Reed II, 2002). Given these, moral identity is significantly associated with prosocial and behavioral tendency that constitute the moral aspects of human flourishing and purposeful life (Han, 2014, 2015; Kristjánsson, 2007). Thus, we could show that moral identity significantly predicted presence of meaning, which is inseparable flourishing (McMahan \& Renken, 2011), in the present study.

While the findings from this study support and extend our existing knowledge of the relationship between moral identity and presence of meaning, there are several limitations that could be addressed in future research. First, participant recruitment was limited to a single state. Second, the search for meaning subscale in MLQ was excluded as presence of meaning more directly predicts well-being outcomes, and it was necessary to shorten the length of the survey form. Future studies should also examine the relationship between moral identity, searching for meaning, and presence of meaning, as it contributes to identity development and well-being in the long term. Third, although identity formation in multiple domains influence positive youth development (Hardy et al., 2013), we focused on only one domain of identity, moral identity in the present study. As a previous study showed that the positive psychological influence of 
cultural identity was diminished after controlling for personal identity (Meca et al., 2017), the influence of moral identity might be indeed the influence of identity in another domain associated with moral identity. Hence, there might be left-out variable bias in the present study that should be tested in future study. Fourth, we had to employ a brief measure for moral identity instead of the moral centrality questionnaire invented by Aquino and Reed II (2002), which provides a more comprehensive measure for moral identity, due to the length of our survey form. Additional studies replicating the findings from the present study with the moral centrality questionnaire would contribute to better generalization. Fifth, the quantitative methods used in our study demonstrated that moral identity predicts meaning in life development, but mixed methods or qualitative research would provide insight into whether the content of meaning in life for youth strong on moral identity is prosocial in nature. Finally, because the present study was based on a two-wave dataset, instead of a longitudinal dataset containing data at more than two time points, we are not able to fully explain the longitudinal trend in the development of moral identity and presence of meaning. In order to conduct more sophisticated longitudinal analyses, such as the growth curve modeling and latent growth modeling, data should have been collected at more than two time points.

This present study is the first two-wave investigation that examines how moral identity predicts presence of meaning during a transitional period in emerging adulthood. Another key strength of this study is that we sought to understand how these various important constructs associated with positive youth development interact and relate to each other. Despite the limitations of this study, the findings extend our current understanding of the relationship between identity and presence of meaning by showing that the relationship between a single identity content (i.e., moral identity) and presence of meaning is not bidirectional. The findings 
from the present study might provide empirical evidence to a group of moral philosophers, psychologists, and educators who emphasize the importance of morality in positive psychology and positive youth development (Han, 2015; Kristjánsson, 2013; Malin et al., 2015). The present study may suggest that teaching moral virtues, moral reasoning, and importance of moral values in human life can contribute to the promotion of flourishing among adolescents and young adults.

Author contribution: HH conceived of the study, participated in data analysis and drafted the manuscript; IL participated in data analysis and helped to draft the manuscript; AK helped to draft the manuscript. All authors read and approved the final manuscript. 


\section{References}

Adams, T. B., Bezner, J. R., Drabbs, M. E., Zambarano, R. J., \& Steinhardt, M. A. (2000). Conceptualization and measurement of the spiritual and psychological dimensions of wellness in a college population. Journal of American College Health, 48(4), 165-173. doi:10.1080/07448480009595692

Aho, K., Derryberry, D., \& Peterson, T. (2014). Model selection for ecologists: the worldviews of AIC and BIC. Ecology, 95(3), 631-636. doi:10.1890/13-1452.1

Aquino, K., Freeman, D., Reed, A., Lim, V. K. G., \& Felps, W. (2009). Testing a SocialCognitive Model of Moral Behavior: The Interactive Influence of Situations and Moral Identity Centrality. Journal of Personality and Social Psychology, 97(1), 123-141.

Aquino, K., \& Reed II, A. (2002). The self-importance of moral identity. Journal of Personality and Social Psychology, 83(6), 1423-1440. doi:10.1037//0022-3514.83.6.1423

Ballard, P. J., Malin, H., Porter, T. J., Colby, A., \& Damon, W. (2015). Motivations for Civic Participation Among Diverse Youth: More Similarities than Differences. Research in Human Development, 12(1-2), 63-83. doi:10.1080/15427609.2015.1010348

Blasi, A. (2013). The self and the management of the moral life. In Handbook of moral motivation (pp. 229-248). Rotterdam: SensePublishers. doi:10.1007/978-94-6209-275-4_14

Brassai, L., Piko, B. F., \& Steger, M. F. (2011). Meaning in life: Is it a protective factor for adolescents' psychological health? International Journal of Behavioral Medicine, 18(1), 44-51. doi:10.1007/s12529-010-9089-6

Bronk, K. C., Hill, P. L., Lapsley, D. K., Talib, T. L., \& Finch, H. (2009). Purpose, hope, and life 
satisfaction in three age groups. The Journal of Positive Psychology, 4(6), 500-510.

doi:10.1080/17439760903271439

Bundick, M. J., Andrews, M., Jones, A., Mariano, J. M., Bronk, K. C., \& Damon, W. (2006). Revised youth purpose survey. Unpublished instrument. Stanford, CA: Stanford Center on Adolescence.

Damon, W. (2008). The path to purpose: Helping our children fnd their calling in life. New York: Free Press.

Erikson, E. (1968). Youth: Identity and crisis. New York, NY: WW. doi:10.1002/yd.29

Freeman, D., Aquino, K., \& McFerran, B. (2009). Overcoming beneficiary race as an impediment to charitable donations: Social dominance orientation, the experience of moral elevation, and donation behavior. Personality and Social Psychology Bulletin, 35(1), 72-84.

Fry, P. S. (2000). Religious involvement, spirituality and personal meaning for life: Existential predictors of psychological wellbeing in community-residing and institutional care elders. Aging \& Mental Health, 4(November 1999), 375-387. doi:10.1080/713649965

Han, H. (2014). Virtue Ethics, Positive Psychology, and a New Model of Science and Engineering Ethics Education. Science and Engineering Ethics. doi:10.1007/s11948-0149539-7

Han, H. (2015). Purpose as a moral virtue for flourishing. Journal of Moral Education, 44(3), 391-309. doi:10.1080/03057240.2015.1040383

Hardy, S. A., Francis, S. W., Zamboanga, B. L., Kim, S. Y., Anderson, S. G., \& Forthun, L. F. (2013). The roles of identity formation and moral identity in college student mental health, 
health-risk behaviors, and psychological well-being. Journal of Clinical Psychology, 69(4), 364-382. doi:10.1002/jclp.21913

Hardy, S. A., Walker, L. J., Olsen, J. A., Woodbury, R. D., \& Hickman, J. R. (2014). Moral identity as moral ideal self: Links to adolescent outcomes. Developmental Psychology, 50(1), 45-57. doi:10.1037/a0033598

Kristjánsson, K. (2007). Measuring self-respect. Journal for the Theory of Social Behaviour, 37(3), 225-242. doi:10.1111/j.1468-5914.2007.00339.x

Kristjánsson, K. (2012). Positive Psychology and Positive Education: Old Wine in New Bottles? Educational Psychologist, 47(2), 86-105. doi:10.1080/00461520.2011.610678

Kristjánsson, K. (2013). Virtues and vices in positive psychology: A philosophical critique. New York, NY: Cambridge University Press.

Little, R. J. A. (1988). A Test of Missing Completely at Random for Multivariate Data with Missing Values. Journal of the American Statistical Association, 83(404), 1198. doi: $10.2307 / 2290157$

Malin, H., Ballard, P. J., \& Damon, W. (2015). Civic purpose: An integrated construct for understanding civic development in adolescence. Human Development, 58(2), 103-130. doi:10.1159/000381655

Malin, H., Han, H., \& Liauw, I. (2017). Civic purpose in late adolescence: Factors that prevent decline in civic engagement after high school. Developmental Psychology. doi: $10.1037 / \operatorname{dev} 0000322$

Malin, H., Reilly, T. S., Quinn, B., \& Moran, S. (2014). Adolescent purpose development: 
Exploring empathy, discovering roles, shifting priorities, and creating pathways. Journal of Research on Adolescence, 24, 186-199. doi:10.1111/jora.12051

McMahan, E. A., \& Renken, M. D. (2011). Eudaimonic conceptions of well-being, meaning in life, and self-reported well-being: Initial test of a mediational model. Personality and Individual Differences, 51(5), 589-594. doi:10.1016/j.paid.2011.05.020

Meca, A., Sabet, R. F., Farrelly, C. M., Benitez, C. G., Schwartz, S. J., Gonzales-Backen, M., ... Lizzi, K. M. (2017). Personal and Cultural Identity Development in Recently Immigrated Hispanic Adolescents: Links With Psychosocial Functioning. Cultural Diversity and Ethnic Minority Psychology. doi:10.1037/cdp0000129

Negru-Subtirica, O., Pop, E. I., Luyckx, K., Dezutter, J., \& Steger, M. F. (2016). The meaningful identity: A longitudinal look at the interplay between identity and meaning in life in adolescence. Developmental Psychology, 52(11), 1926-1936. doi:10.1037/dev0000176

Park, N., Park, M., \& Peterson, C. (2010). When is the Search for Meaning Related to Life Satisfaction? Applied Psychology: Health and Well-Being, 2(1), 1-13. doi:10.1111/j.17580854.2009.01024.x

Peterson, C., Park, N., \& Seligman, M. E. P. (2005). Orientations to happiness and life satisfaction: The full life versus the empty life. Journal of Happiness Studies, 6(1), 25-41. doi:10.1007/s10902-004-1278-z

Phillips, J., De Freitas, J., Mott, C., Gruber, J., \& Knobe, J. (2017). True happiness: The role of morality in the folk concept of happiness. Journal of Experimental Psychology: General, 146(2), 165-181. doi:10.1037/xge0000252 
Porter, T. J. (2013). Moral and political identity and civic involvement in adolescents. Journal of Moral Education, 42(2), 239-255. doi:10.1080/03057240.2012.761133

Rausch, J. R., Maxwell, S. E., \& Kelley, K. (2003). Analytic Methods for Questions Pertaining to a Randomized Pretest, Posttest, Follow-Up Design. Journal of Clinical Child \& Adolescent Psychology, 32(3), 467-486. doi:10.1207/S15374424JCCP3203_15

Reed, A., Aquino, K., \& Levy, E. (2007). Moral identity and judgments of charitable behaviors. Journal of Marketing, 71(1), 178-193.

Reker, G. T., \& Wong, P. T. P. (1988). Aging as an individual process: Toward a theory of personal meaning. In J. E. Birren \& V. L. Bengston (Eds.), Emergent Theories of Aging (pp. 214-246). New York, NY: Springer.

Seligman, M. E. P. (2011). Flourish: A visionary new understanding of happiness and wellbeing. Flourish: A Visionary New Understanding of Happiness and Well-Being.

Smith, C., Christoffersen, K., Davidson, H., \& Herzog, P. S. (2011). Lost in Transition: The Dark Side of Emerging Adulthood. New York, NY: Oxford University Press.

Steger, M. F., Bundick, M. J., \& Yeager, D. (2011). Meaning in Life. In R. J. R. Levesque (Ed.), Encyclopedia of Adolescence (pp. 1666-1677). New York, NY: Springer New York. doi:10.1007/978-1-4419-1695-2_316

Steger, M. F., Frazier, P., Oishi, S., \& Kaler, M. (2006). The meaning in life questionnaire: Assessing the presence of and search for meaning in life. Journal of Counseling Psychology, 53(1), 80-93. doi:10.1037/0022-0167.53.1.80

Steger, M. F., \& Kashdan, T. B. (2007). Stability and specificity of meaning in life and life 
satisfaction over one year. Journal of Happiness Studies, 8(2), 161-179.

doi:10.1007/s10902-006-9011-8

Steger, M. F., Kashdan, T. B., \& Oishi, S. (2008). Being good by doing good: Daily eudaimonic activity and well-being. Journal of Research in Personality, 42, 22-42. doi:10.1016/j.jrp.2007.03.004

Steger, M. F., Kashdan, T. B., Sullivan, B. A., \& Lorentz, D. (2008). Understanding the Search for Meaning in Life: Personality, Cognitive Style, and the Dynamic Between Seeking and Experiencing Meaning. Journal of Personality, 76(2), 199-228. doi:10.1111/j.14676494.2007.00484.x

Steger, M. F., Oishi, S., \& Kashdan, T. B. (2009). Meaning in life across the life span: Levels and correlates of meaning in life from emerging adulthood to older adulthood. The Journal of Positive Psychology, 4(1), 43-52. doi:10.1080/17439760802303127

Strohminger, N., \& Nichols, S. (2014). The essential moral self. Cognition, 131(1), 159-171. doi:10.1016/j.cognition.2013.12.005

Wetherell, G. A. (2015). Morality Provides Meaning. De Paul University. 
Tables

Table 1

Distribution of participants according to gender and ethnicity

\begin{tabular}{llrrr}
\hline & & T1 $n(\%)$ & T2 $n(\%)$ & Attrition rate \\
\hline Gender & Male & $751(48.30 \%)$ & $184(39.15 \%)$ & $75.50 \%$ \\
& Female & $804(51.70 \%)$ & $286(60.85 \%)$ & $64.43 \%$ \\
\hline & Asian & $397(25.53 \%)$ & $162(34.47 \%)$ & $59.19 \%$ \\
& African American & $85(5.47 \%)$ & $22(4.62 \%)$ & $75.00 \%$ \\
& Latino/a & $717(46.11 \%)$ & $189(40.21 \%)$ & $74.12 \%$ \\
& Caucasian & $98(6.30 \%)$ & $29(6.17 \%)$ & $71.41 \%$ \\
& Native American & $5(.32 \%)$ & $0(.00 \%)$ & $100.00 \%$ \\
& Multiethnic & $153(9.84 \%)$ & $43(9.15 \%)$ & $73.62 \%$ \\
& Other & $100(6.43 \%)$ & $25(5.32 \%)$ & $75.00 \%$ \\
& Yes & & $433(92.13 \%)$ & \\
& No & & $37(7.87 \%)$ & \\
\hline
\end{tabular}


Table 2

Results of correlation analyses

\begin{tabular}{|c|c|c|c|c|c|c|c|c|c|c|c|c|c|}
\hline & $M$ & $S D$ & 2 & 3 & 4 & 5 & 6 & 7 & 8 & 9 & 10 & 11 & 12 \\
\hline 1. Moral Identity T1 & 3.25 & $.52-$ & & & & & & & & & & & \\
\hline 2. Moral Identity T2 & 3.21 & $.59 .42 * * *$ & - & & & & & & & & & & \\
\hline 3. Presence of meaning T1 & 3.75 & $.81 .21 * * *$ & $.14 * *$ & - & & & & & & & & & \\
\hline 4. Presence of meaning T2 & 3.62 & $.86 .22 * * *$ & $.31 * * *$ & $.51 * * *$ & & & & & & & & & \\
\hline 5. Female & & $.12 * *$ & $.11 *$ & -.00 & -.01 & & & & & & & & \\
\hline 6. Asian & & $-.12 *$ & $-.16^{* * *}$ & $-.11 *$ & $-.13 * *$ & -.03 & & & & & & & \\
\hline 7. African American & & -.03 & .06 & .01 & .01 & .01 & $-.16^{* * *}$ & & & & & & \\
\hline 8. Latino/a & & .03 & .06 & .04 & .07 & .02 & $-.58 * * *$ & $-.18 * * *$ & & & & & \\
\hline 9. Caucasian & & .06 & -.00 & -.01 & .04 & -.03 & $-.18 * * *$ & -.06 & $-.21 * * *$ & & & & \\
\hline 10. Multiethnic & & .03 & .07 & .05 & -.01 & -.00 & $-.22 * * *$ & -.07 & $-.26 * * *$ & -.08 & & & \\
\hline 11. Other & & $.09^{*}$ & .06 & .08 & .06 & .05 & $-.17 * * *$ & -.05 & $-.19 * * *$ & -.06 & -.07 & & \\
\hline 12. SES & 3.17 & 1.94 .03 & -.01 & $.13^{*}$ & $.13 * *$ & -.03 & .02 & -.00 & $-.16 * *$ & $.13 * *$ & .07 & .06 & \\
\hline 13. T2 college attendance & & .02 & .03 & -.01 & -.03 & .03 & $.10 *$ & -.04 & -.02 & -.05 & -.04 & .04 & -.00 \\
\hline
\end{tabular}

Note. SES: $1=$ the lowest decile of SES; $10=$ the highest decile of SES. $* p<.05,{ }^{*} p<.01, * * * p<.001$. 


\section{Table 3}

Mixed effects model comparison

Dependent variable $=\mathrm{T} 2$ presence of meaning

Only with baseline presence of meaning ( $\mathrm{T} 1$ presence of meaning)

$\begin{array}{llll}4 & -514.97 & 1037.95 & 1054.40\end{array}$

With demographical variables

$\begin{array}{llll}13 & -467.98 & 961.97 & 1013.86\end{array}$

With T1 moral identity

$\begin{array}{llll}13 & -456.30 & 940.32 & 992.07\end{array}$

Dependent variable $=\mathrm{T} 2$ moral identity

Only with baseline moral identity (T1 moral identity)

$\begin{array}{llll}5 & -356.41 & 772.81 & 743.32\end{array}$

With demographical variables

$\begin{array}{llll}12 & -299.59 & 623.18 & 670.87\end{array}$

With $\mathrm{T} 1$ presence of mearning

$\begin{array}{llll}13 & -297.55 & 621.09 & 672.58\end{array}$


Table 4

Mixed effects model ANCOVA of T2 presence of meaning and moral identity

\begin{tabular}{|c|c|c|c|c|c|c|c|c|c|c|}
\hline & \multicolumn{5}{|c|}{$\mathrm{DV}=\mathrm{T} 2$ Presence of meaning } & \multicolumn{5}{|c|}{$\mathrm{DV}=\mathrm{T} 2$ Moral identity } \\
\hline & $B$ & $S E$ & $z$ & $p$ & $95 \% \mathrm{CI}$ & $B$ & $S E$ & $z$ & $p$ & $95 \% \mathrm{CI}$ \\
\hline T1 Moral identity & .17 & .07 & 2.33 & $.02 *$ & {$[.03, .32]$} & .43 & .05 & 8.52 & $.001^{* * *}$ & {$[.33, .53]$} \\
\hline T1 Presence of meaning & .53 & .05 & 11.00 & $.001 * * *$ & {$[.43, .62]$} & .05 & .03 & 1.44 & .15 & {$[-.02, .11]$} \\
\hline SES & .04 & .02 & 1.81 & .07 & {$[-.00, .08]$} & -.01 & .01 & -.59 & .56 & {$[-.04, .02]$} \\
\hline Gender & -.00 & .08 & -.00 & .99 & {$[-.15, .15]$} & .02 & .05 & .40 & .69 & {$[-.08, .12]$} \\
\hline Asian & -.15 & .09 & -1.58 & .12 & {$[-.33, .04]$} & -.02 & .07 & -.33 & .74 & {$[-.15, .11]$} \\
\hline African American & .05 & .18 & .26 & .79 & {$[-.31, .41]$} & .17 & .12 & 1.36 & .17 & {$[-.07,41]$} \\
\hline Caucasian & .01 & .16 & .05 & .96 & {$[-.31, .33]$} & .03 & .11 & .25 & .80 & {$[-.19, .24]$} \\
\hline Multi-ethnicity & -.12 & .14 & -.87 & .38 & {$[-.38, .15]$} & .13 & .09 & 1.43 & .15 & {$[-.05, .31]$} \\
\hline Other & .02 & .20 & .12 & .91 & {$[-.38, .42]$} & .12 & .14 & .84 & .40 & {$[-.16, .39]$} \\
\hline T2 College attendance & -.07 & .16 & -.42 & .67 & {$[-.37, .24]$} & .02 & .10 & .18 & .85 & {$[-.18, .22]$} \\
\hline
\end{tabular}

Note. Latino/a is the reference category for ethnicity as the most participants were from this group. Gender: $1=$ male; $2=$ female. SES: $1=$ the lowest decile of SES; $10=$ the highest decile of SES. College attendance: $1=$ attending; $2=$ not attending. The $\mathrm{T} 1$ independent variable of interest in each analysis was bolded. $* p<.05,{ }^{*} * p<.01, * * * p<.001$ (two-tailed) 


\section{Figures}

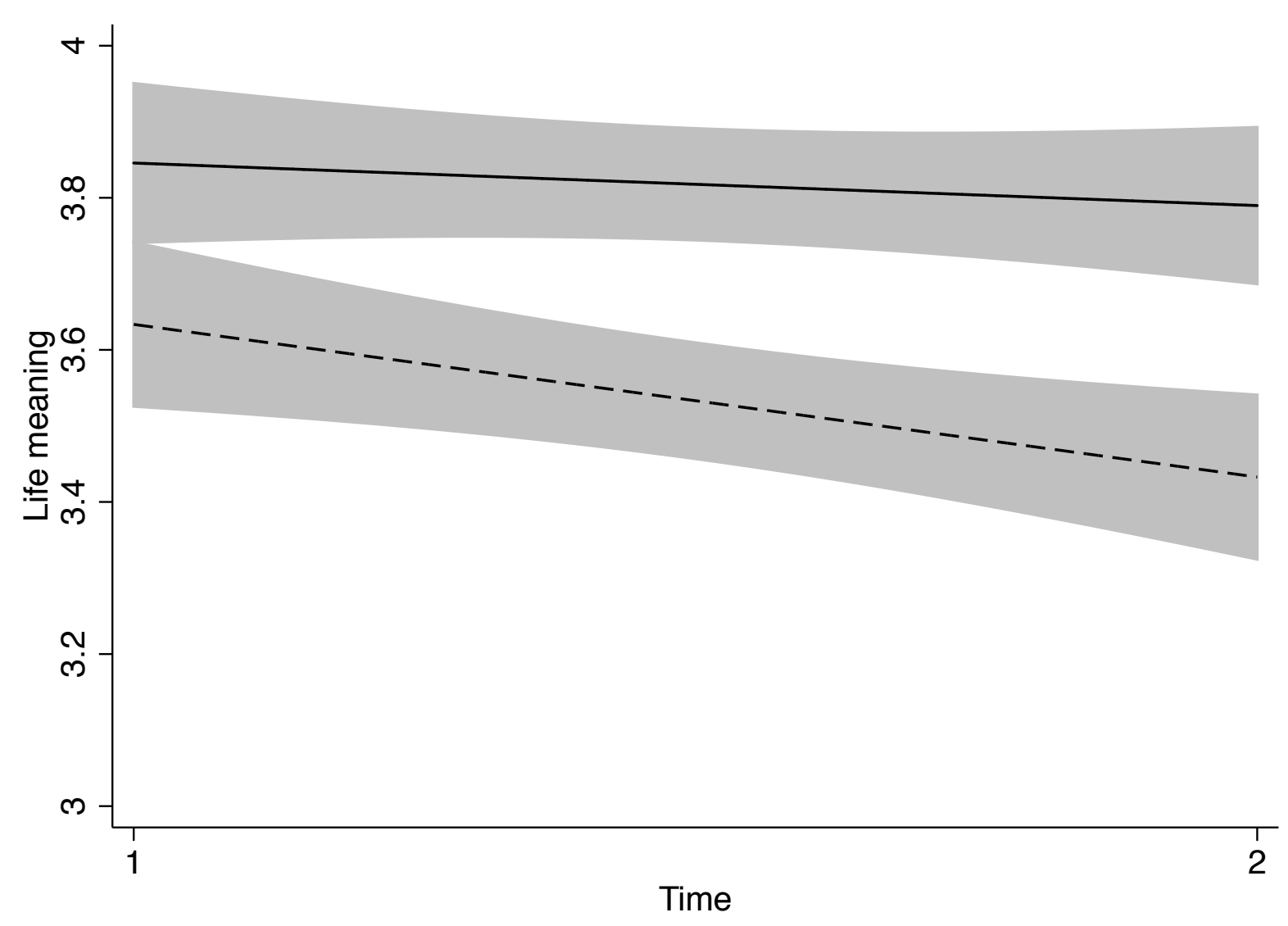

Figure 1. The change in presence of meaning over time among participants with $\mathrm{T} 1 \mathrm{moral}$ identity score higher than the median and those with T1 moral identity score lower than the median with $95 \%$ CI. Solid line: strong moral identity ( $\geq$ median); dash line: weak moral identity $(<$ median). 


\section{Moral Identity Predicts the Development of Presence of Meaning during Emerging Adulthood}

\section{Supplementary Materials}

Moral Identity Questionnaire (Ballard, Malin, Porter, Colby, \& Damon, 2015; Malin, Han, \& Liauw, 2017; Porter, 2013)

Imagine that the drawing below represents you. In the middle circle (4) are things that are very central to who you are as a person. The next circle (3) is the things that are quite central to who you are, and the outer circle (2) is things that are somewhat important to who you are. Things that are not part of your identity belong outside the circles (1). Please think about this drawing when you answer the next question. First, read all items, and then go back and decide how central each of them are to your identity. Even if something seems good but isn't an important part of who you are, you should answer "Not central to my identity."

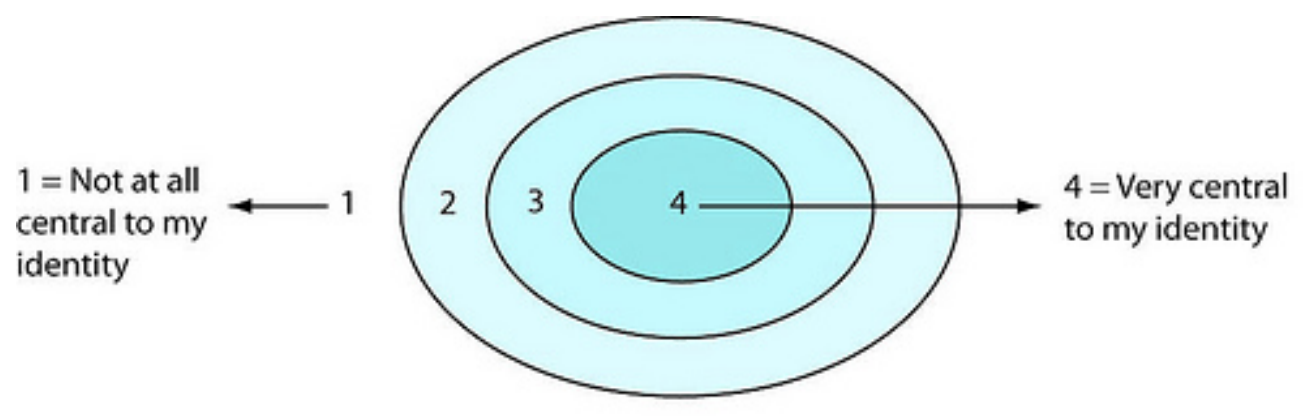


How important are each of the following to your identity?

\begin{tabular}{|c|c|c|c|c|}
\hline & $\begin{array}{l}\text { 1. Not at all } \\
\text { central to my } \\
\text { identity }\end{array}$ & $\begin{array}{l}\text { 2. Somewhat } \\
\text { central to my } \\
\text { identity }\end{array}$ & $\begin{array}{l}\text { 3. Quite central } \\
\text { to my identity }\end{array}$ & $\begin{array}{l}\text { 4. Very } \\
\text { central to my } \\
\text { identity }\end{array}$ \\
\hline Spiritual or religious & $\mathrm{O}$ & $\mathrm{O}$ & $\mathrm{O}$ & $\mathrm{O}$ \\
\hline Smart & 0 & O & O & O \\
\hline Concerned about & & & & \\
\hline international issues & O & 0 & O & O \\
\hline Being fair & O & $\mathrm{O}$ & $\mathrm{O}$ & $\mathrm{O}$ \\
\hline $\begin{array}{l}\text { Willing to stand up for } \\
\text { what I believe is right }\end{array}$ & O & O & O & $\mathrm{O}$ \\
\hline Involved in solving & & & & \\
\hline community problems & $\mathrm{O}$ & $\mathrm{O}$ & O & $\mathrm{O}$ \\
\hline Creative or imaginative & $\mathrm{O}$ & O & O & O \\
\hline Athletic & $\mathrm{O}$ & O & $\mathrm{O}$ & O \\
\hline Politically involved & $\mathrm{O}$ & $\mathrm{O}$ & O & O \\
\hline $\begin{array}{l}\text { Compassionate, concerned } \\
\text { about all kinds of people }\end{array}$ & $\mathrm{O}$ & 0 & O & O \\
\hline Honest & O & O & O & $\mathrm{O}$ \\
\hline $\begin{array}{l}\text { Concerned about } \\
\text { government decisions and } \\
\text { policies }\end{array}$ & $\mathrm{O}$ & $\mathrm{O}$ & O & $\mathrm{O}$ \\
\hline
\end{tabular}




\begin{tabular}{|c|c|c|c|c|}
\hline Rebellious & 0 & 0 & 0 & 0 \\
$\begin{array}{c}\text { Concerned about justice } \\
\text { and human rights }\end{array}$ & 0 & 0 & 0 & 0 \\
Responsible, someone & 0 & 0 & 0 & \\
others can depend on & 0 & 0 & 0 & 0 \\
\hline
\end{tabular}

